\title{
PREPARAÇÃO PARA A APOSENTADORIA: RELATO DE UMA INTERVENÇÃO CLÍNICA NA ABORDAGEM DA PSICOLOGIA POSITIVA
}

\author{
Preparation for retirement: report of a clinical intervention in a Positive Psychology approach \\ Preparación para lajubilación: relato de una intervención clinica en el enfoque de la Psicología Positiva
}

DANIELA PEREIRA DI BONIFÁCIO FABIO SCORSOLINI-COMIN

\begin{abstract}
Resumo: O processo de aposentadoria representa um momento crítico dentro do processo de desenvolvimento. O objetivo deste estudo de caso foi o de descrever e analisar uma experiência de atenção psicológica desenvolvida em um Programa de Preparação de Aposentadoria (PPA) de uma universidade pública federal voltada especificamente para profissionais da educação básica, a partir da abordagem da Psicologia Positiva. Foram realizados 13 encontros individuais com uma professora de 45 anos de idade, nos quais foram trabalhadas as questões envolvendo o reconhecimento de limites, a necessidade de organização e planejamento, bem como a reflexão sobre atividades laborais gratificantes. Concluiu-se que o acompanhamento psicológico na preparação para a aposentadoria não pode se dar de modo dissociado da compreensão crítica acerca das atuais condições de trabalho, motivo pelo qual o adoecimento pelo trabalho pode e deve ser um disparador para que se pense em estratégias de ampliação dos conceitos de saúde e bem-estar.
\end{abstract}

Palavras-chave: Aposentadoria; Trabalho docente; Saúde ocupacional; Aconselhamento psicoterapêutico; Psicologia Positiva.

\begin{abstract}
The retirement process represents a turning-point of development procedure. The main goals of this report were to analyze and describe a psychology attention experience. Developed by a public university, the Retirement Preparation Program uses positive psychology throughout the retirement period of basic education employees. A 45 years old teacherprovided basics information for this report by participating in 13 individual meetings. During those sessions, topics such as, limits recognition, planning and organization necessities, and the reflection of rewarding work activities were discussed. The psychology attention on a preparation of retirement has been concluded as an activity directly related to the work conditions. Often, those work conditions are reasons for illness so, that fact should be a step for a change in concepts of health and wellness.
\end{abstract}

Key words: Retirement; Teaching; Health occupation; Psychotherapeutic attention; Positive psychology.

Resumen: El proceso de jubilación representa un momento crítico en el proceso de desarrollo. El objetivo de este estudio fue describir y analizar una experiencia de atención psicológica desarrollado en un Programa de Preparación la Jubilación de una universidad pública federal dedicada específicamente para profesionales de lo enseñanza primaria, desde el enfoque de la Psicología Positiva. Fue realizado 13 encuentros individuales con una profesora de 45 años, con la que trabajaron temas relacionados con el reconocimiento de los límites, la necesidad de organización y planificación, así como la reflexión sobre las actividades de trabajo gratificantes. Se concluyó que el acompañamiento psicológico en la preparación para la jubilación no puede ocurrir disoció del comprensión crítica de las condiciones de trabajo actuales, razón por lo que la enfermedad en el trabajo puede y debe ser un disparador para hacer pensar en estrategias de expansión de los conceptos de salud y bienestar.

Palabras-clave: Jubilación, Trabajo de la docencia, Salud ocupacional, Asesoramiento psicoterapéutico, Psicología positiva.

\section{Introdução}

A temática da aposentadoria tem recebido atenção especial no contexto nacional diante da anunciada reforma da previdência, em discussão a partir de 2017. Aliada a essa questão encontramos discussões acaloradas em torno do mundo do trabalho, da precarização das condições dos trabalhadores, envelhecimento populacional, saúde do trabalhador, além da garantia de direitos aos trabalhadores, aspectos estes inseridos no universo da aposentadoria (Antunes \& Moré, 2016; Boehs, Medina, Bardagi, Luna, \& Silva, 2017).

Para além desses aspectos de ordem econômica, política e social, o presente estudo debruça-se sobre o processo de preparação para a aposentadoria, haja vista que este período é marcado por uma contradição fundamental: assim como é desejada, esperada, muitas vezes também é temida, promovendo, em alguns casos, ansiedade e sofrimento psíquico decorrentes dessa transição e do modo como o indivíduo se posiciona diante dessa fase (Duarte \& 
Melo-Silva, 2009; Fontoura, Doll, \& Oliveira, 2015; Wang, Henkens, \& Van Solinge, 2011). O processo de aposentadoria representa um momento crítico dentro do desenvolvimento, podendo ser experienciado de modo mais ou menos adaptativo a depender de diversas dimensões como a atual inserção laboral, suas condições de trabalho, bem como as expectativas construídas acerca do futuro (França \& Carneiro, 2009; Nalin \& França, 2015).

A fim de propiciar uma transição mais segura e adaptativa para a fase de aposentadoria, diversas intervenções têm sido desenvolvidas nos contextos organizacionais e clínicos (Leandro-França, Murta \& Villa, 2014). Os chamados Programas de Preparação para a Aposentadoria (PPA) atuam nesse sentido, propondo reflexões sobre esse processo de preparação, que envolve tanto aspectos negativos como positivos, operando-se a necessidade de desenvolvimento de estratégias adaptativas que compõem, por exemplo, a reconstrução de projetos de vida, a busca pelo bem-estar e a valorização dessa etapa do ciclo vital como importante na aquisição de aprendizados (França \& Soares, 2009).

Segundo Leandro-França, Murta e Villa (2014), o planejamento para a aposentadoria é um conjunto de comportamentos complexos, englobando diversas dimensões da vida que compõem a identidade. Assim, o processo de preparação para a aposentadoria pode ser definido como essa etapa que envolve o levantamento de expectativas, o reconhecimento de necessidades e a adoção de estratégias relacionadas não apenas à interrupção de um período de atividades laborais, mas também a aspectos como saúde e relacionamentos interpessoais, em uma compreensão mais ampla sobre carreira e educação ao longo da vida. De acordo com Murta et al. (2014), os PPAs devem incluir discussões sobre ocupação, finanças, moradia, saúde e relações sociais e afetivas, além de aspectos legais da aposentadoria, corroborando com uma perspectiva mais integral de atenção e cuidado nssa fase da vida.

Diante das repercussões emocionais da fase de aposentadoria, diversas intervenções têm sido balizadas no sentido de acompanhar o indivíduo tanto na etapa de preparação quanto após a aposentadoria, sendo que diferentes abordagens psicológicas têm sido empregadas para o delineamento dessas propostas. No presente estudo, o foco recai sobre o processo de preparação para a aposentadoria, discutindo como podem ser delineadas intervenções para uma melhor travessia desse período, tendo como norte uma proposta clínica desenvolvida a partir da Psicologia Positiva (Scorsolini-Comin \& Poletto, 2016).

Os profissionais da educação representam uma categoria de particular interesse quando se discute a aposentadoria e o desenvolvimento profissional (Viana \& Mourão, 2016). Isso porque, socialmente, observa-se cada vez mais um desprestígio associado a esse fazer profissional, com constantes relatos acerca das dificuldades experienciadas em todos os níveis de ensino, sumarizadas na baixa remuneração, precárias condições de trabalho, políticas inadequadas de progressão de carreira, adoecimento em decorrência do trabalho, além de forte pressão social acerca da efetividade dessa atuação (Silva, 2015). Observa-se que 50\% desses trabalhadores relatam não terem se preparado para a aposentadoria (Gvozd, Sakai, \& Haddad, 2014).

Diversos fatores podem e devem ser analisados na compreensão da aposentadoria especificamente dos docentes, como a qualidade de vida no trabalho, jornada de trabalho, interação com os colegas e sentido construído acerca do papel do professor (Gümüş, Hamarat, Çolak, \& Duran, 2012). Assim, é mister que esses profissionais possam contar com apoio profissional ao longo do processo de preparação para a aposentadoria, momento no qual podem ser trabalhados aspectos como o enfrentamento de expectativas e anseios profissionais e pessoais diante desse momento de vida.

No que se refere ao gênero associado predominantemente ao profissional da educação, sobretudo no nível básico, é importante ainda observar nesse contexto a representação do papel feminino na sociedade trabalhista e consequentemente na aposentadoria, em que as conquistas femininas (entrada no mercado de trabalho, aumento da escolaridade, responsabilidade por despesas da casa) permitiram novas possibilidades, com maiores conquistas no espaço social, fazendo com que essas mulheres se sintam mais independentes e produtivas (Moreira, 2011; Santos \& Marques, 2013; Silva, 2015).

A partir dessa consideração têm emergido diferentes propostas interventivas, entre elas as que visam a criação de um espaço que possibilite orientação e acompanhamento psicológico nessa fase como forma de proporcionar maior reflexão e enfrentamento dessa etapa que acaba sendo ambígua, por gerar sentimentos de crise tanto quanto de liberdade. Os programas de preparação para a aposentadoria visam auxiliar o trabalhador a usufruir melhor o tempo nessa nova fase, proporcionando maior bem-estar por instigar maior reflexão sobre os pontos positivos, amparando a discussão de melhores alternativas para lidar com as adversidades desse momento, a adoção de novas práticas por um estilo de vida mais saudável (França, 1999, 2002; Lytle, Clancy, Foley \& Cotter, 2015; Murta et al., 2014; Pazzim \& Marin, 2016; Soares, Costa, Rosa \& Oliveira, 2007; Zanelli, Silva \& Soares, 2010).

Esses programas também auxiliam um envelhecer com dignidade. Apesar do expressivo aumento da expectativa de vida nos últimos anos, a sociedade ainda valoriza os meios de produção, colocando o trabalho como centralidade de vida e fazendo com que os indivíduos não estejam preparados para esse processo, sendo necessária uma reconstrução de valores e descoberta de potencialidades, lidando com angústias e incertezas, abordando questões como controle dos gastos financeiros, o cuidado com a saúde (atividade física e alimentação saudável), valorização do lazer, possibilidade de novas atividades/carreira, vínculos e contato social (Murta et al., 2014).

Embora os programas de preparação para a aposentadoria façam uso de diferentes estratégias didáticas e de reflexão, que podem incluir palestras, 
aulas, discussões, visitas, oficinas e rodas de conversa, por exemplo, abre-se cada vez mais espaço para se pensar como essas pessoas podem também ser auxiliadas a partir de intervenções psicológicas com foco na aposentadoria. A partir disso, têm emergido propostas de aconselhamento psicológico voltadas a esse público (Scorsolini-Comin, 2015), com o apoio de distintas abordagens teóricas, dentre as quais destacamos, neste estudo, a Psicologia Positiva. Esta abordagem se propõe a recuperar e desenvolver as experiências positivas e as forças dos indivíduos como formas de enfrentamentos das situações desfavoráveis e de conflito (Scorsolini-Comin, Fontaine, Koller \& Santos, 2013), com ênfase na promoção de saúde e de bem-estar (Paludo \& Koller, 2007; Park \& Peterson, 2007).

Embora não seja expressiva a produção científica sobre a psicoterapia desenvolvida a partir da Psicologia Positiva, nem sejam traçadas diretrizes claras e rígidas para tais intervenções (Scorsolini-Comin \& Poletto, 2016), observa-se que as experiências existentes têm se mostrado bastante ecléticas, dialogando diretamente com autores como Rogers e Maslow, considerados precursores desse referencial, na década de 1950, cujo foco recai sobre a potencialização das capacidades humanas, a busca por florescimento, crescimento e pelo pleno desenvolvimento.

Antunes e Moré (2016) afirmam que no contexto nacional há a carência de estudos que explorem as relações entre aposentadoria e saúde do trabalhador, bem como entre saúde do idoso e saúde do trabalhador, com o direcionamento de ações para os ambientes organizacionais. Aliado a isso, a preparação para a aposentadoria é um aspecto que vem sendo cada vez mais valorizado nas diversas intervenções no contexto do trabalho (Murta et al., 2014; Zanelli, Silva, \& Soares, 2010), compreendendo que se trata de uma transição laboral importante e com diferentes ressonâncias também em termos psicológicos (Costa \& Soares, 2009).

A escuta clínica desse processo, portanto, tem acenado para um locus de estudo e intervenção. Considerando o breve panorama traçado e a necessidade de veiculação de iniciativas desenvolvidas nesses programas interventivos, aliado às necessidades específicas da categoria docente, o objetivo deste estudo foi o de descrever e analisar uma experiência de atenção psicológica desenvolvida em um Programa de Preparação de Aposentadoria (PPA) de uma universidade pública federal voltada especificamente para profissionais da educação básica, a partir da abordagem da Psicologia Positiva.

\section{Método}

\section{Tipo de estudo}

Trata-se de um relato de experiência profissional a partir de um estudo de caso único, escolhido pela possibilidade de detalhamento acerca do percurso interventivo (Yin, 2015). A participação tanto no programa quanto no estudo foi voluntária e consentida pela cliente (nome fictício) por meio da assinatura do Termo de Consentimento Livre e Esclarecido, respeitando-se todos os aspectos éticos. A intervenção foi autorizada pela Pró-Reitoria de Extensão Universitária da instituição (Registro PROEXT 059.15).

\section{Experiência analisada}

Foram analisadas as experiências obtidas a partir de um projeto de extensão universitária realizado conjuntamente com um estágio profissionalizante em Psicologia, com ênfase na área de processos clínicos. As intervenções ocorreram por meio de encontros realizados entre a cliente - uma profissional da educação básica - e uma extensionista do quinto ano do curso de Psicologia, supervisionada por dois profissionais da área.

Essas intervenções psicológicas foram conduzidas em uma instituição de ensino de uma cidade de médio porte da região do Triângulo Mineiro, Estado de Minas Gerais. Os atendimentos psicológicos realizados pela extensionista foram escolhidos como forma de estudo por proporcionarem uma visão ampliada sobre o Programa de Preparação para a Aposentadoria (PPA), onde se pode perceber a evolução da cliente com relação a diferentes aspectos, como será abordado na discussão do caso.

O objetivo do projeto de extensão à comunidade era de facilitar a transição entre o mercado de trabalho e a aposentadoria, otimizando recursos pessoais em termos de autoconhecimento, promovendo bem-estar psicológico e autonomia para a resolução adequada de conflitos. O aconselhamento psicológico empregado nas intervenções teve como base a abordagem da Psicologia Positiva, que visa a recuperar as potencialidades do indivíduo, por meio da capacitação do mesmo, no intuito de possibilitar o enfrentamento de situações desfavoráveis e de conflito, buscando por experiências positivas e desenvolvimento de recursos pessoais (Nalin \& França, 2015; Park \& Peterson, 2007; Paludo \& Koller, 2007; Scorsolini-Comin, 2015; Scorsolini-Comin et al., 2013; Scorsolini-Comin \& Poletto, 2016).

\section{Procedimento}

O contato inicial com a participante se deu pela divulgação do programa na instituição em que a mesma exercia sua profissão. A partir disso, a mesma demonstrou interesse e foi contatada posteriormente para a realização do primeiro atendimento e estabelecimento do rapport. Foram realizados 13 encontros com duração de aproximadamente uma hora cada, no serviço-escola da instituição de origem dos autores, com o intuito de fornecer um ambiente sigilo e um ambiente privado que assegurasse a privacidade e o conforto material e psicológico da participante.

Todos os encontros foram registrados a partir de um diário de campo, bem como a partir do preenchimento de uma ficha (Scorsolini-Comin, 2015) com espaços para anotações tanto acerca de fatos observados e relatados como de impressões e reflexões realizadas pelo estagiário durante e após o 
atendimento. Também havia espaço para que o estagiário destacasse suas dúvidas acerca do caso e do atendimento, o que era levado para as supervisões e discutido nas reuniões clínicas.

Assim, o corpus analítico foi composto pelas transcrições dos atendimentos e das reflexões contidas em diários de campo. O corpus foi lido minuciosamente, a fim de recuperar tanto o registro da atividade (o que foi realizado a cada encontro, as decisões da cliente e o modo como o caso foi manejado pela psicoterapeuta em formação) como refletir sobre o modo que a intervenção foi desenvolvida, tendo como norte a literatura científica acerca do aconselhamento psicológico aplicado à gestão de carreiras e também a partir da abordagem clínica da Psicologia Positiva (Roepke \& Seligman, 2015; Scorsolini-Comin, 2015; Scorsolini-Comin \& Poletto, 2016).

\section{Resultados e Discussão}

Regina (nome fictício) tinha 45 anos de idade à época da intervenção (2015) e trabalhava como educadora em duas escolas, uma no berçário (Educação Infantil) no período da manhã e a outra à noite na educação de jovens e adultos (EJA). Regina procurou o programa de preparação para a aposentadoria após divulgação do serviço na escola em que trabalhava no período da manhã. Inicialmente relatou que ainda lhe restavam cinco anos para se aposentar e que o ambiente de trabalho estava sendo muito estressante e desgastante para a mesma, desenvolvendo depressão e até algumas crises vinculadas à exaustão pelo trabalho.

Suas principais queixas estavam associadas a uma falta de interesse no ambiente de trabalho, pelo mesmo ter se tornado um fator estressante; dificuldade de organização com relação às suas atividades; e o fato de apresentar uma cobrança interna muito alta, fazendo com que a mesma se dedicasse exaustivamente às suas responsabilidades e para com os outros. A literatura científica não é uníssona quanto aquando deve se iniciar o processo de preparação para a aposentadoria. Alguns autores também reconhecem que esse processo não se finda com a aposentadoria, podendo ser estendido até mesmo cinco anos após a mesma (França \& Soares, 2009). Considerando que o PPA da instituição na qual foram coletados os dados era aberto a todos os servidores, sendo divulgado prioritariamente às pessoas que estavam a cinco de se aposentarem formalmente (Scorsolini-Comin, 2015) e que entre as demandas da cliente estavam queixas relativas ao mundo do trabalho na interface com a aposentadoria, pode-se destacar que a cliente deste caso estava em processo de preparação para a aposentadoria. Sua queixa principal era referente à sua saúde, diretamente envolvida com o seu trabalho e as cobranças impostas pelo meio, corroborando a necessidade de se investigar mais a fundo as relações entre a aposentadoria e a saúde do trabalhador (Antunes \& Moré, 2016) e possibilitando a compreensão de que a preparação para a aposentadoria é um processo amplo, complexo e que articula questões de ordem laboral, de saúde e bem-estar, bem como experiências pessoais e de relacionamentos interpessoais (França \& Soares, 2009; Leandro-França, Murta \& Villa, 2014).

Tendo em consideração esses aspectos trazidos pela cliente, o intuito do aconselhamento psicológico, de acordo com os pressupostos da Psicologia Positiva, foi acolher a cliente, buscando o resgate do seu bem-estar, em uma perspectiva mais ampla de carreira. Esse primeiro momento visou permitir a criação de um clima de acolhimento e de confiança no vínculo que estava começando a se estabelecer, visando com que a cliente reconhecesse suas vivências e potencialidades de forma a conseguir lidar com as adversidades.

A partir do rapport, os principais objetivos delimitados foram: (1) trabalhar o reconhecimento de limites, sem que se cobrasse demais e conseguindo delimitar fronteiras entre o que estava ao seu alcance e o que não poderia ser feito pela mesma; (2) organização, como uma forma de melhor funcionamento do espaço, em que a mesma pudesse se sentir mais calma por apresentar maior controle sobre suas atividades, mas acima de tudo como uma forma de reservar períodos que fossem destinados a ela mesma; (3) reconhecer suas vivências e atividades de forma a se destinar a uma nova maneira de atuação que possibilite a criação de um novo contato com sua realidade, desenvolvendo novos prazeres em sua atuação profissional e um novo significado sobre a mesma. Na Figura 1 é possível obter maiores informações sobre a realização das sessões e os principais pontos trabalhados em cada um dos encontros, de forma a conseguir uma melhor visualização da forma como se destinaram as sessões, bem como a evolução da cliente.

$\mathrm{O}$ aconselhamento psicológico surge como uma prática que visa a facilitar uma adaptação mais satisfatória de um sujeito a uma determinada situação na qual se encontra, buscando assim aperfeiçoar seus recursos em termos de autoconhecimento e autonomia, no intuito de promover maior qualidade de vida e bem-estar para o sujeito (Scorsolini-Comin, 2015). No caso apresentado, o principal enfoque abordado é a questão da aposentadoria, na busca de uma preparação para determinado evento. No entanto, de acordo com a cliente, ainda havia cinco anos para a aposentadoria, de modo que sua principal dificuldade estava vinculada ao enfrentamento de seu ambiente de trabalho, haja vista que a mesma já não apresentava motivação frente a uma atividade que se mostrava tão estressante e desprazerosa. Assim, as intervenções pautaram-se não apenas na questão da aposentadoria, mas também, de modo mais geral, em uma reflexão sobre o mundo do trabalho e como isso estava gerando sofrimento na cliente.

Em uma perspectiva mais ampla de atenção à saúde do trabalhador, pode-se considerar que a fase de preparação para a aposentadoria não deve incluir apenas elementos que possam habilitar o sujeito para quando cessarem suas atividades laborais, mas também reflexões sobre problemáticas enfrentadas em seu dia-a-dia, direta ou indireta- 


\begin{tabular}{|c|c|c|c|}
\hline$\#$ & $\begin{array}{l}\text { Objetivo } \\
\text { norteador }\end{array}$ & Resumo da sessão & Intervenção \\
\hline $1^{\circ}$ & Rapport. & $\begin{array}{l}\text { Dificuldades e estresse no ambiente } \\
\text { de trabalho. Dois empregos. Crise } \\
\text { nervosa e vontade de se aposentar. }\end{array}$ & $\begin{array}{l}\text { Escuta e acolhimento com relação às } \\
\text { vivências, busca de maior contato e } \\
\text { investigação sobre os sentimentos da mesma. }\end{array}$ \\
\hline $2^{\circ}$ & $\begin{array}{l}\text { Conhecer suas } \\
\text { atividades. }\end{array}$ & $\begin{array}{l}\text { Ressalta se cobrar muito } \\
\text { internamente, tentando dar seu } \\
\text { máximo e muitas vezes chegando à } \\
\text { exaustão. }\end{array}$ & $\begin{array}{l}\text { Escuta e acolhimento com relação às } \\
\text { vivências. }\end{array}$ \\
\hline $3^{\circ}$ & $\begin{array}{l}\text { Investigar mais } \\
\text { a sua } \\
\text { autocobrança. }\end{array}$ & $\begin{array}{l}\text { Resgata a questão de se cobrar e } \\
\text { como isso acaba sendo incentivado } \\
\text { pela sociedade. }\end{array}$ & $\begin{array}{l}\text { Investigação com relação as áreas de interesse, } \\
\text { como forma de resgatar significados por } \\
\text { atividades que lhe gerassem prazer. }\end{array}$ \\
\hline $4^{\circ}$ & $\begin{array}{l}\text { Conhecer suas } \\
\text { escolhas } \\
\text { profissionais. }\end{array}$ & $\begin{array}{l}\text { Conta sempre gostar de crianças, } \\
\text { artes e trabalhos manuais, } \\
\text { influenciando na sua escolha por se } \\
\text { tornar educadora. }\end{array}$ & $\begin{array}{l}\text { A partir das experiências positivas no } \\
\text { ambiente de trabalho, possibilitar uma visão } \\
\text { mais positiva acerca de sua atuação. }\end{array}$ \\
\hline $5^{\circ}$ & $\begin{array}{l}\text { Investigar sobre } \\
\text { atividades } \\
\text { gratificantes no } \\
\text { trabalho. }\end{array}$ & $\begin{array}{l}\text { Relato de atividade que lhe dá } \\
\text { prazer no trabalho (contar estórias). }\end{array}$ & $\begin{array}{l}\text { Incentivar a questão de enfrentamento das } \\
\text { situações como forma de reforçar sua } \\
\text { autonomia, resgatando a questão de voltar a } \\
\text { realizar atividades que lhe geram prazer. }\end{array}$ \\
\hline $6^{\circ}$ & $\begin{array}{l}\text { Acompanha- } \\
\text { mento }\end{array}$ & $\begin{array}{l}\text { Realização de curso de contar } \\
\text { estórias e destacou situações nas } \\
\text { quais se sente desconfortável no } \\
\text { ambiente de trabalho. }\end{array}$ & $\begin{array}{l}\text { Estimular a conversa sobre atividades } \\
\text { gratificantes como forma de gerar } \\
\text { reconhecimento de si e de seus limites, tanto } \\
\text { quanto de suas habilidades, possibilitando } \\
\text { nova forma de enxergar sua atuação. }\end{array}$ \\
\hline $7^{\circ}$ & $\begin{array}{l}\text { Possibilitar um } \\
\text { redescobrimento } \\
\text { de si e de suas } \\
\text { habilidades. }\end{array}$ & $\begin{array}{l}\text { Percebe melhoras, salientando que } \\
\text { percebia novos pontos que deveriam } \\
\text { ser melhorados como a questão da } \\
\text { sua falta de organização. }\end{array}$ & $\begin{array}{l}\text { Reflexão e autoconhecimento, enfatizando } \\
\text { seus avanços principalmente frente à } \\
\text { segurança e autoconfiança. }\end{array}$ \\
\hline $8^{\circ}$ & $\begin{array}{l}\text { Acompanhar } \\
\text { atividades } \\
\text { realizadas. }\end{array}$ & $\begin{array}{l}\text { Conta sobre como foi gratificante } \\
\text { participar de um evento sobre sua } \\
\text { profissão. }\end{array}$ & $\begin{array}{l}\text { Resgate acerca do potencial do seu ambiente } \\
\text { de trabalho para superar desafios e } \\
\text { dificuldades. }\end{array}$ \\
\hline $9^{\circ}$ & $\begin{array}{l}\text { Trabalhar a } \\
\text { questão da falta } \\
\text { de organização. }\end{array}$ & $\begin{array}{l}\text { Tenta se organizar, definindo o } \\
\text { tempo que deve ser vinculado ao } \\
\text { trabalho, lazer e atividades de casa. }\end{array}$ & $\begin{array}{l}\text { Refletir sobre possibilidade de organização do } \\
\text { dia a dia, destinando um tempo para o cuidado } \\
\text { de si, realizando atividades como forma de }\end{array}$ \\
\hline
\end{tabular}


mente relacionadas ao trabalho, haja vista que a aposentadoria se insere no ciclo de vida de modo integrado, não exclusivamente no universo laboral. Essa recomendação está alinhada aos pressupostos discutidos por Murta et al. (2014), no sentido de explorar, no processo de preparação para a aposentadoria, aspectos que ultrapassem o mundo do trabalho, incluindo, por exemplo, saúde e relações sociais e afetivas. Além disso, o trabalho pode e deve ser concebido como um elemento essencial na vida dos sujeitos, balizando também aspectos como bem-estar e satisfação com a vida, como salientado na perspectiva da Psicologia Positiva e pela literatura na área de aposentadoria (França \& Soares, 2009; Scorsolini-Comin, 2015), em uma abordagem mais integrativa.

A revisão do seu atual momento de vida, balizada a partir das queixas em relação ao seu trabalho, possibilitou uma ampla reflexão sobre atividades prazerosas e investimento em si mesma, o que posteriormente pode ser empregado como estratégia ao longo de sua aposentadoria. O aposentar-se, desse modo, não precisa ser experienciado como a interrupção absoluta do movimento produtivo, mas disparar a maior apropriação acerca de atividades que envolvam prazer, satisfação e sentido de vida, redefinindo de modo positivo essa fase do ciclo vital (Nalin \& França, 2015).

Há que se considerar que a aposentadoria, podendo ocorrer por diversos motivos e em diferentes etapas do ciclo vital, pode disparar várias possibilidades de percursos, como a retomada do trabalho após a aposentadoria, o desenvolvimento de outras atividades (remuneradas ou não), até mesmo a ausência de planejamento pós-carreira (Zanelli et al., 2010). Vemos, no caso de Regina, que a preocupação com a aposentadoria acaba sendo menor que o sofrimento relatado em seu cotidiano de trabalho, o que pode ser compreendido dentro de sua história de vida e de suas características, como a idade e sua dupla jornada de trabalho. Como se trata de uma pessoa ativa e que desempenha diversas atividades (não apenas em seus dois empregos), a aposentadoria parece não se resumir à finalização de um processo ou vínculo trabalhista, como relatado pela mesma nos atendimentos, mas justamente mais um evento com o qual ela precisa lidar, assim como os compromissos que assume em seu cotidiano e que promovem angústia e desamparo. Esses diversos aspectos puderam ser considerados e acolhidos na escuta clínica da cliente a partir da experiência narrada no presente estudo. Embora muitos PPAs priorizem atividades que possam ser mais diretamente associadas à aposentadoria, como o planejamento de vida e as dúvidas legais sobre o processo, abrir espaço para queixas emergentes nesse período é também uma forma de contribuir na preparação para a aposentadoria. Considera-se, portanto, que a intervenção clínica foi importante para ampliar esse cenário, abarcando mais aspectos que podem compor uma queixa no processo de preparação e dando destaque para um elemento premente, que é a capacidade laboral daquele que irá se aposentar. Essa pessoa ainda pode ser bastante ativa, de modo que ouvir suas queixas acerca do trabalho também é um modo de entender que tais reflexões fazem parte de um continuum em direção à aposentadoria, ou mesmo em uma abordagem de educação ao longo da vida.

Nos atendimentos, Regina se mostra ansiosa para poder se aposentar, alegando que só assim conseguirá aproveitar seu tempo e descansar de toda a tensão de seus dois empregos. O período de espera de cinco anos para a aposentadoria mostra-se um empecilho nesse sentido, fazendo com que a mesma desenvolvesse crises e um estado depressivo por não aguentar as pressões do ambiente de trabalho. Foi necessário compreender o significado dessas vivências para a cliente e auxiliá-la a encontrar novos meios para que o caminho de espera para a aposentadoria conseguisse ser gratificante.

Como exemplo, a cliente salientava ter prazer em sua profissão, porém sentia que o ambiente estava cobrando demais dela mesma, não conseguindo delimitar fronteiras entre o que estava ao seu alcance e o que não poderia ser feito por ela. A partir disso, o ponto inicial foi gerar uma reflexão de forma com que ela pudesse reconhecer seus limites, fazendo suas atividades obrigatórias de acordo com aquilo que era possível, apresentando maior consciência das situações e não se culpando por algo que estaria além de seus limites e condição física-mental.Foi trabalhada também a questão da organização como uma forma de melhor funcionamento do espaço, em que a mesma pudesse se sentir mais calma por apresentar maior controle sobre suas atividades, mas acima de tudo como maneira de obter períodos que fossem destinados a ela mesma, como um descanso, uma leitura, entre outros, sendo um recurso para conseguir enfrentar as situações estressantes do dia a dia.

As sessões foram programadas com o intuito de focalizar em um problema específico trazido pela paciente - no caso, vinculado à preparação para a aposentadoria - possibilitando um espaço de escuta e acolhimento em que a mesma pudesse se sentir segura para compartilhar suas dificuldades, proporcionando um momento de compreensão e de reflexão frente às situações e sentimentos vivenciados. A partir disso, as conversas se direcionaram identificando os aspectos que atrapalhavam o bem-estar da cliente, como o estresse, extrema tristeza e exaustão, variáveis estas que também emergiam em seu período de preparação para a aposentadoria e que estão diretamente associadas não apenas às suas condições de trabalho (jornada, remuneração, tipo de atividade executada, por exemplo), mas também a aspectos psicológicos e características pessoais (como a ansiedade, necessidade de desempenhar múltiplas tarefas, pouca abertura à reflexão e ao autocuidado, por exemplo).

O principal aspecto abordado foi a questão de reconhecer suas vivências e atividades de forma a se destinar a uma nova maneira de atuação que possibilite a criação de um novo contato com sua realidade, criando novos prazeres em sua atuação profissional, destinando-se a cursos e atividades gratificantes para a mesma (como contar estórias 
para crianças e teatro), como forma de possibilitar um lugar mais seguro e que não se tornasse tão estressante, fazendo com que seu trabalho voltasse a ser um lugar de satisfação pessoal, onde a mesma pudesse se sentir à vontade, mais autêntica e integrada.

Dessa forma, o aconselhamento psicológico se mostrou um suporte para que a mesma conseguisse lidar com as pressões sofridas em seu ambiente de trabalho, como em relação às suas chefias e algumas dificuldades interpessoais nesse relacionamento. Foram realizadas diversas reflexões sobre o trabalho em si, reconstruindo novos interesses e atividades mais prazerosas que pudessem ser desenvolvidas nesse contexto. Assim, observou-se, ao longo dos encontros, que Regina ampliou o repertório de visões associadas ao trabalho, desenvolveu habilidades que resgataram sua autonomia e autocontrole, apresentando maior confiança em si e descobrindo novos significados em suas vivências, o que promoveu maior disponibilidade para lidar com as adversidades inerentes ao mundo do trabalho e também ao cotidiano familiar. O programa de preparação para a aposentadoria, aqui narrado a partir de uma intervenção clínica, mostrou-se necessário enquanto ferramenta para a reflexão acerca desse período, do mundo do trabalho e suas condições concretas, bem como aspectos intimamente associados a essa fase, como a promoção de saúde e bem-estar.

Compreende-se que a experiência de adoecimento mental decorrente do trabalho (estresse, burnout, ansiedade e depressão), que também emergiu nos atendimentos à Regina, pode ser acolhida na proposta clínica aqui descrita justamente por se compreender a preparação para a aposentadoria enquanto um período amplo, diverso e complexo, acenando para vários enfoques e possibilidades de condução do trabalho clínico. Abrir-se às diferentes queixas que permeiam esse período de preparação pode ser útil no sentido de potencializar uma compreensão mais ampla acerca da aposentadoria e, consequentemente, da saúde do trabalhador, como recuperado na literatura científica (Antunes \& Moré, 2016; Nalin \& França, 2015). O preparar-se para a aposentadoria, portanto, pode envolver a recuperação, a promoção e a potencialização de recursos pessoais em uma perspectiva ampliada e contextualizada de atuação (França \& Carneiro, 2009; Scorsolini-Comin, 2015), inserindo realmente a aposentadoria em um cenário de educação para a vida (França \& Soares, 2009).

Para tanto, o acompanhamento psicológico na preparação para a aposentadoria não pode se dar de modo dissociado da compreensão crítica acerca das atuais condições de trabalho, motivo pelo qual o adoecimento pelo trabalho pode e deve ser um disparador para que se pense em estratégias de ampliação do conceito de saúde do trabalhador (Antunes \& Moré, 2016; Gvozd, Sakai \& Haddad, 2014; Moreira, 2011; Santos \& Marques, 2013; Silva, 2015). Ajudar o cliente na busca pelo sentido em seu trabalho, bem como maior flexibilização e organização da atividade produtiva, podem ser importantes no sentido de aliviar sintomas e desenvolver estratégias potentes diante de cenários por vezes extenuantes. Obviamente que tais intervenções podem e devem ser associadas a estratégias de saúde do trabalhador perseguidas pelas organizações de trabalho.

\section{Considerações finais}

A partir dos pressupostos da Psicologia Positivista, o acompanhamento psicológico na preparação para a aposentadoria visou enfatizar a busca pelo bem-estar, almejando uma reflexão sobre as vivências positivas e negativas como forma de possibilitar uma maior compreensão de si próprio, criando consequentemente melhores relações no ambiente social e no enfrentamento de situações. Foi possível entrar em contato com o real sujeito e suas vivências, de forma a fazer com que Regina conseguisse compreender suas experiências, no intuito de perceber o que não era saudável e construir recursos como forma de superação, de maneira com que a mesma pudesse se reconhecer e, a partir de maior conhecimento de si, concretizar possíveis mudanças.

Com maior autonomia e capacidade reflexiva, Regina adaptou-se melhor diante de suas condições de trabalho, estando melhor preparada para a futura aposentadoria. Como encaminhamento do caso, foi sugerido que Regina continuasse em atendimento, agora em um processo psicoterápico mais profundo, o que foi aceito pela cliente como possibilidade de acompanhamento de sua evolução. Seu caso foi assumido por outra estagiária e os atendimentos clínicos continuaram por mais um ano e meio, sob a mesma equipe de supervisão.

A intervenção com professores tem se mostrado potente no sentido de ofertar uma reflexão acerca do ambiente de trabalho, as atividades realizadas cotidianamente, bem como o maior foco nas práticas gratificantes e que contribuem para a ampliação de sentidos positivos acerca do trabalho (Nalin \& França, 2015; Roepke \& Seligman, 2015). Desse modo, a preparação para a aposentadoria ocorreu de modo indissociável de uma reflexão mais atenta acerca do próprio trabalho (Murta et al., 2014). O aconselhamento deve abrir espaço tanto para reflexões sobre a futura aposentadoria como para a análise dos recursos e das possibilidades já existentes no trabalho realizado, o que permite maior vinculação a atividades prazerosas e promotoras de bem-estar. Tais estratégias são apoiadas pela Psicologia Positiva, constituindo um norte para intervenções com essa demanda e com esse mesmo público em preparação para a aposentadoria.

A esse caso único tem sido incorporada uma gama expressiva de relatos de outros atendimentos a docentes dentro da mesma experiência investigada. Os resultados da análise desses atendimentos podem contribuir para novas investigações no campo da aposentadoria e disparar propostas interventivas junto a docentes, notadamente da educação básica, a partir dos direcionadores aqui compartilhados e discutidos a partir da Psicologia Positiva. Os programas de preparação para aposentadoria, portanto, podem intervir com foco na promoção do 
bem-estar e no desenvolvimento de potencialidades como forma de o indivíduo criar um suporte para lidar com as adversidades inerentes ao processo de aposentadoria. Apesar de o presente estudo tratar de uma modalidade de atendimento breve, lança-se importantes direcionadores para o planejamento de intervenções clínicas a partir da Psicologia Positiva, o que deve ser acompanhado por meio de mais pesquisas e constantes follow-ups.

\section{Referências}

Antunes, M. H., \& Moré, C. L. O. O. (2016). Aposentadoria, saúde do idoso e saúde do trabalhador: revisão integrativa da produção brasileira. Revista Psicologia Organizações e Trabalho, 16(3), 248-258. doi: 10.17652/rpot/2016.3.681

Boehs, S. T. M., Medina, P. F., Bardagi, M. P., Luna, I. N., \& Silva, N. (2017). Revisão da literatura latino-americana sobre aposentadoria e trabalho: perspectivas psicológicas. Revista Psicologia Organizações e Trabalho, 17(1), 54-61. doi: 10.17652/ rpot/2017.1.11598

Costa, A. B., \& Soares, D. H. P. (2009). Orientação psicológica para a aposentadoria. Revista Psicologia: Organizações e Trabalho, 9(2), 97-108.

Duarte, C. V., \& Melo-Silva, L. L. (2009). Expectativas diante da aposentadoria: Um estudo de acompanhamento em momento de transição. Revista Brasileira de Orientação Profissional, 10(1), 45-54.

Fontoura, D. S., Doll, J., \& Oliveira, S. N. (2015). O desafio de aposentar-se no mundo contemporâneo. Educação \& Realidade, 40(1), 53-79.

França, L. H. (1999). Preparação para aposentadoria: desafios a enfrentar. In R. Veras (Org.), Terceira idade: alternativas para uma sociedade em transição (pp. 11-34). Rio de Janeiro: Dumará/UnATI.

França, L. H. (2002). Repensando aposentadoria com qualidade: um manual para facilitadores de programas de educação para aposentadoria. Rio de Janeiro: UnATI/UERJ.

França, L. H., \& Carneiro, D. (2009). Programas de preparação para a aposentadoria: Um estudo com trabalhadores mais velhos em Resende (RJ). Revista Brasileira de Geriatria e Gerontologia, 12(3), 429-448.

França, L. H. F. P., \& Soares, D. H. P. (2009). Preparação para a aposentadoria como parte da educação ao longo da vida. Psicologia: Ciência e Profissão, 29(4), 738-751. doi: 10.1590/S1414-98932009000400007

Gümüş, M., Hamarat, B., Çolak, E., \& Duran, E. (2012). Organizational and occupational identification: Relations to teacher satisfaction and intention to early retirement. Career Development International, 17(4), 300-313. doi: 10.1108/13620431211255806

Gvozd, R, Sakai, A. M., \& Haddad, M. C. L. (2014). Sen- timentos e perspectivas de trabalhadores de instituição universitária pública frente à aposentadoria. Revista Mineira de Enfermagem, 19(1), 79-83.

Leandro-França, C., Murta, S. G., \& Villa, M. B. (2014). Efeitos de uma intervenção breve no planejamento para a aposentadoria. Revista Psicologia Organizações e Trabalho, 14(3), 257-270.

Lytle, M. C., Clancy, M. E., Foley, P. F., \& Cotter, E. W. (2015). Current trends in retirement implications for career counseling and vocational Psychology. Journal of Career Development, 42(3), 170-184. doi: 10.1177/0894845314545785

Moreira, J. O. (2011). Imaginário sobre a aposentadoria, trabalho, velhice: estudo de caso com professores universitários. Psicologia em Estudo, 16(4), 541550. doi: 10.1590/S1413-73722011000400005

Murta, S. G., Abreu, S., França, C. L., Pedralho, M., Seidl, J., Lira, N. P. M., Carvalhedo, R. K. M., Conceição, A. C., \& Gunther, I. A. (2014). Preparação para a aposentadoria: implantação e avaliação do Programa Viva Mais! Psicologia: Reflexão e Crítica, 27(1), 1-9. doi: 10.1590/S0102-79722014000100001

Nalin, C. P. \& França, L. H. F. P. (2015). The importance of resilience for well-being in retirement. Paidéia, 25(61), 191-199. doi: 10.1590/198243272561201507

Paludo, S. S., \&Koller, S. H. (2007). Psicologia Positiva: Uma nova abordagem para antigas questões. Paidéia (Ribeirão Preto), 17(36), 9-20.

Park, N., \& Peterson, C. (2007). Methodological issues in Positive Psychology and the assessment of character strengths. In A. D. Ong \& M. H. M. van Dulmen (Eds.), Oxford Handbook of methods in Positive Psychology (pp. 292-305). New York: Oxford University Press.

Pazzim, T. A., \& Marin, A. (2016). Programas de preparação para aposentadoria: revisão sistemática da literatura nacional. RevistaBrasileira de OrientaçãoProfissional, 17(1), 91-101

Roepke, A. M. \& Seligman, M. E. P. (2015). Doors opening: A mechanism for growth after adversity. Journal of Positive Psychology, 10(2) 107-115. doi: 10.1080/17439760.2014.913669

Santos, M. N., \& Marques, A. C. (2013). Condição de saúde, estilo de vida e característica de professores de uma cidade do sul do Brasil. Ciência \& Saúde Coletiva, 18(3), 837-846. doi: 10.1590/S141381232013000300029

Scorsolini-Comin, F. (2015). Aconselhamento psicológico: aplicações em gestão de carreiras, educação e saúde. São Paulo: Atlas.

Scorsolini-Comin, F., Fontaine, A. M. G. V., Koller, S. H., \& Santos, M. A. (2013). From authentic happiness to well-being: the flourishing of Positive Psychology. Psicologia: Reflexão e Crítica, 26(4), 663-670. 
Scorsolini-Comin, F., \& Poletto, M. (2016). Psicologia Positiva na prática clínica: princípios, reflexões e questionamentos. In B. L. Seibel, M. Poletto, \& S. H. Koller (Orgs.), Psicologia Positiva: teoria, pesquisa e intervenção (pp. 189-201). Curitiba: Juruá.

Silva, E. P. (2015). Adoecimento e sofrimento de professores universitários: dimensões afetivas e ético-políticas. Psicologia: Teoria e Prática, 17(1), 61-71. doi: 10.15348/1980-6906/psicologia.v17n1p61-71

Soares, D. H. P., Costa, A., Rosa, A. M., \& Oliveira, M. L. (2007). Aposenta-ação: Programa de preparação para a aposentadoria. Estudos Interdisciplinares sobre o Envelhecimento, 13, 123-134.

Viana, V. R., \& Mourão, L. (2016). Percepção dos docentes do ensino fundamental sobre seu desenvolvimento profissional. Revista Brasileira de Orientação Profissional, 17(1), 55-65.

Wang, M., Henkens, K., \& Van Solinge, H. (2011). Retirement adjustment: A review of theoretical and empirical advancements. American Psychologist, 66(3), 204-213.

Yin, R. K. (2015). Estudo de caso: Planejamento e Métodos. Porto Alegre: Bookman.

Zanelli, J. C., Silva, N., \& Soares, D. H. P. (2010). Orientação para aposentadoria nas organizações de trabalho: Construção de projetos para o pós-carreira. Porto Alegre: Artmed.
Daniela Pereira Di Bonifácio é Psicóloga pela Universidade Federal do Triângulo Mineiro, com Especialização em Saúde Mental pela Universidade de Ribeirão Preto e Aprimoramento Profissional pelo Programa Multiprofissional em Hipertensão Arterial e Diabetes Mellitus da Secretaria de Saúde de Ribeirão Preto/SP.

Fabio Scorsolini-Comin é Doutor em Psicologia pela Universidade de São Paulo, com Pós-doutorado em Tratamento e Prevenção Psicológica pela mesma instituição. Docente do Departamento de Enfermagem Psiquiátrica e Ciências Humanas da Escola de Enfermagem de Ribeirão Preto da Universidade de São Paulo (EERP-USP). Bolsista de Produtividade em Pesquisa do CNPq.

Recebido em 04-01.17 Primeira Decisão Editorial em 14.04.18 Aceito em 25.06.18 